Int. J. Electrochem. Sci., 16 (2021) Article ID: 210746

\title{
Detection of $\alpha$-Ethinyl Estradiol in Water by Voltammetry: Mechanistic Study and Practical Implications
}

\author{
Zepeng Qian, Shashi Lalvani* and Lei L. Kerr* \\ Dept. of Chemical, Paper and Biomedical Engineering, Miami University, Oxford, Ohio, 45056 \\ *E-mail: kerrll@miamioh.edu, lalvansb@miamioh.edu
}

doi: $10.20964 / 2021.07 .09$

Received: 31 January 2021 / Accepted: 29 March 2021 / Published: 31 May 2021

\begin{abstract}
Residue amounts of synthetic estradiol; an active ingredient of oral contraceptives finds its way into water bodies. Estrogenic effects on aquatic life as well as on humans and other land animals are of great health concerns. A carbon-based screen-printed disposable electrode was used to detect $\alpha$-Ethinyl Estradiol by cyclic voltammetry. The data analysis shows that the observed one electron oxidation peak is irreversible. The mechanism of reaction primarily involves adsorption of $17-\alpha$-Ethinyl Estradiol (EE2) on the surface of the electrode. The rate constant and adsorption capacity were estimated to be $1.46 \mathrm{~s}^{-1}$ and $1.3 \times 10^{-10} \mathrm{moles} / \mathrm{cm}^{2}$. The peak current vs concentration relationship was found to be linear over the range of concentration investigated. In addition, data on repeatability, sensitivity and detection limits are provided.
\end{abstract}

Keywords: Cyclic voltammetry, estradiol, biosensor, disposable electrode

\section{FULL TEXT}

(C) 2021 The Authors. Published by ESG (www.electrochemsci.org). This article is an open access article distributed under the terms and conditions of the Creative Commons Attribution license (http://creativecommons.org/licenses/by/4.0/). 